\title{
How "Pulaaku” Moral Value Influence Nomadic Fulani Perception and Non-Participation in Educational Community Development in Ikara District, Kaduna, Nigeria
}

\author{
Suleiman Dahiru (Corresponding author) \\ Dept. of Social and Development Sciences, Faculty of Human Ecology \\ Universiti Putra Malaysia, 43400, Serdang, Selangor, Malaysia \\ $\&$ \\ Dept. of Sociology, Faculty of Arts Social and Management Science \\ Yobe State University, PMB 1144 Damaturu, Yobe State, Nigeria \\ Tel: 601-0275-6303 E-mail: sdjamaajamaa9@gmail.com
}

\section{Nobaya binti Ahmad}

Dept. of Social and Development Sciences, Faculty of Human Ecology

Universiti Putra Malaysia, 43400, Serdang, Selangor, Malaysia

Tel: 603-8946-7069Ｅ-mail: nobaya@upm.edu.my

Wan Munira Wan Jaafar

Dept. of Social and Development Sciences, Faculty of Human Ecology

Universiti Putra Malaysia, 43400, Serdang, Selangor, Malaysia

Tel: 603-8946-7048Ｅ-mail: wanmunira@upm.edu.my

Received: November 24, 2016 Accepted: January 29, 2017 Published: March 27, 2017

doi:10.5296/ijssr.v5i1.10355 URL: http://dx.doi.org/10.5296/ijssr.v5i1.10355 


\section{Abstract}

Pastoral Fulani nomads are among the marginalized and educationally disadvantageous communities in Nigeria, and many African countries. Since education remained the mechanism for individual, community and national developments, such groups need to be given attention for the success of sustainable development goal in African nations. To achieve this, human, as well as sociocultural hindrances associated with their educational development need to be evaluated. Therefore, this study explore how pulaaku moral value influences the understanding and perception of the nomadic Fulani in education as the precipitating factor for non-participation in education in Ikara district. Two themes emerged as the findings; firstly Perception of the pastoral Fulani on education generally. Secondly factors precipitating non-participation, is presented into subthemes; strict adherence to pulaaku moral values, fear of fragmentation of social capital, lack of role model and parent ignorance. Thus, the study concluded that Fulani pastoral communities have positive perception on education, but it was evident that socio-cultural factors such as lacking role model with pulaaku principle, perception in fear of the system as a threat to social capital and ignorance influenced their low participation. Hence, there is the need for policymakers, government agencies and stakeholders to have an in-depth conceptual understanding of the Fulani values through funding ethnographic research project, and possibly integrate its ideas and those factors in the design of an acceptable nomadic education system particularly the pulaaku. Also, integrate community-based volunteer groups, purposively for advocacy and awareness will enhanced the group understanding and participation in educational community development.

Keywords: Pastoral Fulani, Educational development, Perception, Pulaaku (Moral values)

\section{Introduction}

Pastoralism is a system of keeping livestock such as cattle, sheep and goat as a source of survival, always in constant movement from one place to another in search of pasture and water. The pastoral community is often stereotyped or perceived as people rejecting basic education; though, education is a key component in the society, and play an important role in human and community development. However, educating the pastoral community is a classic problem in social and development science. Thus some stakeholders argue as reported (Saad, 2002; Amadi, 2015), that investing in education for the group is regarded a waste of resources. The fact that pastoralists are always on the move in search of pasture for their cattle, several efforts made and policies put in place to enable them access education has been hindered over time (Iro, 2006). Central to the discipline of social and development sciences is the concept of education. Thus, it is with the vision of achieving the sustainable development goals SDGs-four of envisaging the world with literacy globally, and access to equitable quality education to everyone globally, with the hope of transforming our world by 2030 (UN, 2015). In light of the recent event in education, it is becoming extremely difficult to ignore the existence of high illiteracy, dropout and marginalization in education. It is a fact in 2013, youth within the ages of fifteen to twenty-four years totaling about one hundred and twenty-three million are still lacking in basic education skills in reading and writing 
(UNESCO-EFA., 2013). The low achievement reported majorly in the sub-Saharan African nations, Nigeria inclusive. Where a number of out-of-school children was confirmed to be high (Power, 2015). As reported in the Education for All Development Index (EDI) pointers of improvement concerning four EFA goals that, Universal Primary Education, quality of education, adult literacy, and gender parity, that generally about thirty nations in sub-Saharan Africa, south, and west Asia fell below 0.8. It was argued that the nations were challenged with multiple issues in terms of low school participation, poor quality in education, high adult illiteracy and are marked with gender inequalities (UNESCO-EFA., 2013).

It was claimed that reaching the marginalized community with accessible education was a global concern (UNESCO, 2010). It is within the ambits of the Education for All goal, for all children to have access to quality education regardless of their gender, ethnicity, location and economic status without any form of discrimination (UNESCO, 2000). Until now, reaching the rural community that is conceded hard to reach with the basic education has remained an undefeated challenge (Sharma, 2011). Consequently, millions of children in these community's' achieved very low or insignificant educational achievement in terms of enrolment, retentions and completion in education (UNESCO, 2010). Scholars have argued that historically, the discrimination and marginalization in education, particularly to the pastoral community group, was a known fact (Bishop, 2008; Dyer, 2010). As it was attributed to the groups' nomadic culture of migration in search of good pasture, water and environment for their livestock (Carr-Hill, Ashete, Sedel, \& de Souza, 2005), coupled with the dearth of research on the nomadic education particularly in Nigeria (Umar \& Tahir 2000, Usman, 2006) to know what education to community development is to the Fulani nomadic group.

Thus, a concern is much in educational achievement of rural communities in Nigeria, as the dropout rate is much to increase, with about 8,290,000 youngsters out of school. The dropout rate is higher in the rural areas with $7,196,846$ constituting 36 percent than urban with $1,092,701$ constituting 12 percent, and among young women with 31 percent than young men with 25.5 percent in Nigeria. The rate is higher in north western and north eastern states, Nigeria according to Demographic Health survey 2008 as cited (EPDC, 2013). Evidence from the report shows that the nomads had just 519,081 enrollment in 2013 (EFA, 2015) out of the one-third of 9.5 million nomadic population that are children of school age. Even though, Kaduna state government has established about 135 schools across the state for the nomads (Bah-Lalya, Tahir, Onocha, \& Sukon, 2012), to educate the Fulani nomadic community; though, figures in 2006 indicated that only 28494 nomadic children were reported to enroll in Kaduna state (Bah-Lalya et al., 2012).

Unfortunately, little is known on scientific understanding of the pastoral Fulani perception and why the poor participation in educational community development in the state. As argued by Umar \& Tahir (2000), most of the early research utilized the quantitative and structured survey approach, which was argued could not go in-depth in understanding the groups' perception in education. As asserted by Sharma (2011), the need to investigate to know what basic education, content and values are to the pastoral community group. This insight would help in understanding their perception. Although, no study was found that seek to investigate the how pulaaku moral value influence Fulani nomadic community perception and 
precipitating factor for the poor participation in educational community development in Ikara district of Kaduna state; therefore, the purpose of this study is to explore how pulaaku moral value of the pastoral Fulani community influence their perception and understanding to education and to answer the question, why the low participation of the Fulani in educational community development in Ikara district keep on persisting.

\section{Literature Review and Contexts}

Research into education has a long history and its importance. Hamman, (2006), confirms that, education is the ways in which people learn or acquire skills, and gain knowledge and understanding about the world, and themselves. Even though, meaning in the concept is constructed differently by others, that influence participation or not. Since perception involves the process of sensation and interpretation, though the interpretation of any stimulus also requires past experience. Rao, V. S. P. And Narayana, P. S (1998) asserted that the perceptual inputs are first received such as the objects, people, etc and then processed by the perceiver through selection, organization and interpretation. And the resultant output becomes the lease of the behavior through the processing mechanism, such as feelings, actions, attitudes, etc. is derived. As such behavior is dependent on these perceived outputs. Hence, social perception is a construction of an understanding of the social world through the data we gather from our senses (Michener, DeLamater, \& Myers, 2004).

The nomadic Fulani pastoralists account for about $6.8 \%$ of the total 140 million population in Nigeria, these communities are spread in 31 states of the Federation, of Nigeria. The total number of Fulani pastoralist, predominantly one-third of the nomadic population are children of school age and need basic educational attention for their inclusion in the national development and economic growth (Aderinoye, Ojokheta, \& Olojede, 2007). Unfortunately, the story of the Nigerian Fulani nomadic pastoralist is often described based on their necessary needs, as those lacking accessibility to basic social needs of good food, clean water, health care, clothes, or shelter. Similarly, they are characterized as lacking in basic literacy skills and access to basic education (Aderinoye et al., 2007).

The Fulani, group has a strong moral cultural value known as 'pulaaku' social capital (Kratli, 2001) That refers to the social relationships within a community that include trust, norms, and social networks (Green \& Haines, 2011) these play a significant role in the livelihood of the pastoralist (Kratli, 2001). However, the Fulani were more known for their usual culture of herding and migration in search of water, pasture and good environment for their herds. Riesman (1998) defined pulaaku as a moral code of conduct or way of being proper to Fulani ethnic group. The concept of pulaaku can also be understood as a set of behavior that occurs in many areas of life such as in language, privacy, human relationships, etc. through deeds, behaviors or attitudes (Ibrahim, 2014). According to Saleh Momale, pulaaku encompasses shyness, patience, self-esteem, and self-respect. It also embodies bravery, deep empathy or love, wisdom and hard work. Hence, it is an all-inclusive moral value, that every Fulani nomads are mandated to live by its creeds (Ujorha, 2014). For any form of behavior contrary to the pulaaku values, a member is considered an outcast often liable to social sanction.

Factors evidently in marginalization and discrimination of Fulani pastoralists, have resulted 
in the low level of educational achievement in terms of enrollment, transition, attendance and gender disparities in this pastoral communities even below the national average (Kratli \& Dyer, 2006). Consequently, the group are excluded in the democratic, educational policy planning and decision making (Raymond, 2012). Furthermore, quite a few types of research have shown that various factors limit minority groups and pastoral community access to social services and education inclusive (Dyer, 2010; Dyer, Anteliz, Coombes, \& Danaher, 2008; KAUNGA, 2005). Few research studies revealed that the cultural values, social belief and attitude were among factors that influenced their understanding and low participation in education among the pastoral communities (Aikman \& Unterhalter, 2005; Warrington \& Kiragu, 2012).

Even though, as Raymond (2012), asserted that pastoral community has a positive and negative stance in education for personal and community development. Similarly, Rao (2006) in his study reported that Bakkarwals perceived education to their children especially the boys as to imply to the future economic well-being of their sons, as a source of wealth, prestige, and a security for the pastoral parents at old age. A study in Somalia by the African education trust further defined the educational perception of the pastoral nomad and needs based on their sociocultural and economic perception as what is "appropriate to our culture and environment (AET, 2008). It is a fact that the nomadic pastoral value to education was on the basis of their socio-economic and cultural stance. Hence from the above claims, the question of why the nomadic recorded low educational achievement is raised.

Raymond (2012) and Usman (2006), asserted that in spite of the aspirations and thoughts, the pastoral community had on educational community development, the opportunities are blocked by the community's cultural values and the attitude of the parents in their strict adherence to the culture of pastoralism. It appeared as a ghost which threatens Fulani value identity known as Pulaaku. As one Fulani leader memorably put it: 'We are not opposed to getting our children into schools but we fear that at the end of it, they will only be good for eating cattle instead of tending and caring for them' (Nkinyangi 1980, cited in (Usman, 2006). These uncertainty in the formal education was reported in Eastern Kenya, Nigeria, and other parts of the sub-Saharan Africa were dominant the pastoral communities are Muslims. (Rotech \& Koros, 2015). Thus, the problem of poor participation of the pastoral group in education is beyond distance to school from community (Migosi, Auma, \& Ombuki, 2013), underfunding (Iro 2006; Usman 2006; Aderinoye et al. 2007) and teacher truancy and lack of teacher supervision (Atinnmo et al. 2011), rather the need for research to explore the understanding of the group perception in education and the precipitating factors in poor participation in the educational community development.

\section{Methodology and Research Area}

The study utilized a qualitative case study approach, because a case can be a thing, a single entity, unit around which there are boundaries. Thus, case can be a person, a program, a group, a specific policy and so on (Merrian, 2009) was used, to understand the perception of nomadic Fulani on educational community development, as well as factors precipitating their low participation. The study was restricted to Ikara district, located north-east of the city of 
Zaria in Kaduna State, north-west Nigeria, with a geographical coordinates of $11^{\circ} 11^{\prime} 0^{\prime \prime}$ North, $8^{\circ}$ 14' 0" East, in Africa (Map landia, 2016). The district is predominantly populated by Hausa and Fulani tribes, whose occupation is majorly farming and animal rearing (Commission, 2010). With the permission of the District Head, the Local Education Secretary and participants consent, twelve participants and three Fulani settlement were purposively located. As the main aim was to locate the information-rich participants (Merriam, 2009). The participant could be delineated into ten Fulani male parents, a nomadic teacher and a district nomadic education desk officer. The reason for the choice of male parents is based on the knowledge of the culture of the Fulani group, as the power and decision to take children or withdrew them from school is on the male parents (Tilde, 2005). Data was collected through the interview, which usually covered a minimum of fifteen to maximum of one hour with participant, from August to September 2015. The interviews were conducted in Hausa language and translated into the English language by a research assistant. The transcript was later send to participant to cross check and a senior expert in linguistics also prove-read and validated the translation. All interview process was guided by a structured open-ended questions. The interview were tape recorded and transcribed. The data was analysed as described by Merrian (2009), all the transcript were line numbered and a double line space between the interviewer and the participant response. All transcript were coded, compared across interviews base on the research objective. Thematically, themes were inductively derived and rephrased as the subheading to show the thought and perception of the Fulani nomadic community to education and the precipitating factors for the community poor participation to the educational development. This theme was on the basis of insight the researcher has on the culture of the Fulani moral value from (Riesman, 1998, Ujorh, 2014b and Ibrahim, 2014).

\section{Result and Discussion}

Based on the data obtained, two themes derived that include; perception of pastoral Fulani on educational community development. Factors precipitating the poor participation were further rephrased into four subthemes.

\subsection{Educational Community Development; Perception of the pastoral Fulani}

Education as a process and ways in which people learn or acquire skills and gain knowledge and understanding about the world and themselves. In this study, it was established that nomadic Fulani has a positive view of the education as a tool that shapes individual moral life, thus making him a good tool for community development. As some participants asserted that education as.....

“....ingredient for the well-being of people... one that has no knowledge is like an animal... as such a community without education are likely to be exposed to moral decadence and would be in darkness for they can't see".

"is a living tree that is not dried up"... and "a community without education is like a dead tree... hence could not build the community but would only be in suffering and difficulty".

Corroborated Larsen \& Hassan (2001) study in Hawarri pastoral community, education is 
seen as a guidance for individual to be informed and be of good behavior wisdom in stealing of despot, navigate the forest, midwife and kind to others. Those without education are worthless and for women, she is considered irresponsible person who can easily be deceived. This result may be further explained by the fact that pastoral Fulani nomadic community constructs ideas based on their social world. As shown above, education demonstrated as a necessity to a comfortable, and harmonize social well-being; thus, described as a living tree, (believed to produce good fruit for the use of the family and community). Hence, pastoral Fulani acknowledge education as acquired skills, ideas and experience that help in developing the individuals to grow and utilized in developing the community. Hence, an educated individual is understood as the force and tool for developing the community. Furthermore, corroborated O'Connor, (1957) assertion that education is a general investment necessary and an enabling factor opening up many outlooks of personal, community and national development. He further argued that its necessity for human in order to articulate self and achieve fullness. For the survival of human in any nation, education is a necessity (Carr, 1997).

Interestingly, no differences in the general and the pastoral Fulani nomads' standpoint in educational community development, as it was uncovered that, lacking in education and knowledge exposes individuals and the community to underdevelopment. These could further be supported by the assumptions of human capital theory on education as capacity building for community development. The belief is that education will help to improve security and reduce conflict, empower the woman, improve health and economic growth of the pastoral community (Appiah \& McMohan, 2002). But this development should be guided by the cultural value as argued by Schwartz (2006).

\subsection{Educational community development; Factors Precipitating low participation}

Surprisingly, basic education to the pastoral group was found to have a second thought by the community, even though, itis understood to be a foundation upon which all other discipline, experience, professionalism and skills is built on (UNESCO, 2007). These result would be better understood by the fact that pastoral Fulani's standpoint on the system is justified with reasons that emerge in the four subthemes as factors influenced by the pulaaku moral value precipitating the low participation in educational development in Ikara district.

\subsubsection{Strict adherence to pulaaku cultural values and belief}

As mention in the literature review, the existence of the code of conduct among the pastoral Fulani group believed to be an identity for every member of the group. Hence, it must be observed at all times. However, in this study it was found that basic education system to the pastoral Fulani community is likely to erode the main principle of the pulaaku by its operation as commented by participant: that withdrawal or refusal to enroll their children in the formal school. It was argued that most schools are dominated by other native and not the Fulani native who do not understand the pulaaku moral value. Hence, Fulani parent feared that the principle of moral values and identity would be eroded as they mix up and interact with others outside Fulani natives. Therefore, believe to be part of the principle of Islam, as any attitude or behavior that is unhealthy is liable to be rejected and such is learn in the 
formal school. For example, being too clever, not being generous, stinginess, laziness, not willing to help in the community.

One of the most important aspect of the finding is that pastoral community are interested in the basic education, surprisingly, the moral values of the pulaaku social capital, that define the identity of the Fulani is not compromised by the group (Usman, 2006). This is in agreement with Ezeomah (1997) assertion that the nomads do not dislike education but rather not comfortable with the method of delivery. It could be argued that policy makers in education did pay little consideration to the pulaaku value. These are in line with the assumption of the cultural value orientation theory, that in the embedded culture, cultural values are adhered to as such social structure is organized and shaped on the basis of that values, encourage and maintain the status quo in respect to coherence, tradition and custom and solidarity. Thus, programme, ideas, behavior not incompatibility with the values could attract tension, revolt and rejection (Schwartz, 2006). As said one of the participant

Hmm he smile.... "some have refused enrolling their children, and some withdrew their kids, because everything was viewed unhealthy ... as you allow your child to be enrolled in a school dominated by Hausa ethnic or any other ethnic group, it is assumed that the child will learn not to be loyal to his parents... kids that are into constant interaction with other tribes will have that Kara da Kawaici (pulaaku) values been polluted in them... this also is believed as parts of the main principle of Islam"

Even though, it is the characteristic of nomadic school in Nigeria combination of natives and ethics either as teachers or students (Usman, 2006). It is, therefore, likely that such a connection exists as a factor, as concluded by a nomadic native teacher that,

“....nomadic Fulani parent would not agree to send their children to the formal school dominated by other native...

Therefore the result supported Rotich \& Koro (2015) finding that, the fear and mistrust of the system of education is the fact that, it would transform and inculcate into them western values orientation which they perceived to be contrary to the pulaaku moral value and Islam. Corroborating the above finding also with the perception of one respondent in a study in Cameron, she said among the Mbororo Fulani natives in Cameron that "an educated girl is spoiled and does not belong to Mbororo norms" (Berinyuy \& Spreen, 2015). Hence, therefore, it is proven that pulaaku moral cultural value is a factor, which is not much highlighted in the literature though found to be a principal factor to the poor participation of the Fulani pastoral group in educational development in Ikara district.

\subsubsection{Fears in fragmentation of the social capital}

The second finding in this study further strengthens the first mentioned that shows, the social structure of the Fulani pastoral community is accompanied with a strong social capital among members. In helping, trust, the network of relationship. One interesting finding was that parent decision on poor participation in the education of their children was argued to be in the worries and the family fear on community sustenance which bonded them together. As it was established one of the participants expressing his worrisome experience of a family member; 
he said

"since he had the opportunity of education, there was no time he agreed to be of benefit to anybody in the family, instead he was good at the sales of the cattle.... He was not been convinced to stay in one place to seek for a permanent job, he always proves to be clever than everyone. ....but he only acknowledged to sell the animals and lavished the money....This was what scared us away from this formal education"

This fear and behaviour are perceived to be the payback of the basic education. This result corroborated Nkigangi (1980) findings of a similar position of a pastoral leader in the literature (Usman, 2006). Leggent (2005) further argued that this standpoint speaks the mind of both the poor and rich families among the pastoral community (Rotich \& koro, 2015). This perception in the payback of the education system influence parents worries and decision either (Saad, 2002), therefore, leads to Fulani poor participation in formal education. This result further supported Kratli (2001), in his report of Karanmanjo pastoral community study, as asserted that parents worries on the education, that it changes the attitude of the nomadic child, as it's distanced him far away from the community, family expectation and sometimes disappeared and never to return to the community to contribute to the family and community development. It is interesting to know that, the disappearance of the child after schooling, is liable to expose the family to socio-economic challenges. One participant further mentioned that.

... any form of cleverness from our understanding... this Boko school education make one to be cleverer .......any person that show too much cleverness, such a person will never reach a compromise with him in what so ever...but only look down on us, as people who knows nothing"

These challenges created a wide gap between the Fulani social capital. However, this finding possibly explains pastoral Fulani parents' perception in the education system as the outcome is proven as a threat to the family source of survival, as it distances children from participating in the family economic system of pastoralism. Corroborated the result of Dyer and Chokes, (1997) work in Rabari Kuchis of India show that elders expressed worries on the negative impact of the formal education to course fragmentation in their social capital (cited Kratli, 2001). Hence, a parent had to decide either for education or pastoralism. The decision is always in favor of the pastoral occupation than education as argued by Rotch \& Koro (2015) in their work.

\subsubsection{Lack of Role Model}

Role models are the everyday visual acts of people they appreciate and wish to copy (Ombati, 2015). This finding confirmed the pulaaku social bond among the Fulani has however influence the group perception of the significance of role model to the pastoral Fulani level of participation in community development project. The disappearance of such a person's i.e role model could lead to setback in participation as one of the participants claims that

"I do feel uncomfortable whenever I observed my situation of lacking education for my children to follow suit, just because we lack someone that could lead us on the importance of 
this (formal education)"

However, these was in agreement with Victor F and Usman report result that in most of the arid-semi areas or nomadic pastoral community, children wish to be educated, but identifying teachers, women gender in the case of girls and male gender for the boys is challenging, whom they can see, consult and motivate them is an issue (Victor F, 2010, Usman, 2006). A nomadic teacher mention;

"if schools were built in a Fulani community without someone as a role model that will be sensitizing them and reorienting them, he believes there is a long way to go"

Rotich and Koros (2015), further argued that role modelling goes a long away in influencing the pastoral parents and the community to education. Lack of role model in pastoral Fulani community makes parent, students and community not to be ambitious and with any problem slightly, they drop out or are withdrawn from the system. Therefore, it is interesting to understand that these findings are less highlighted in most of the reports as a factor influencing the poor participation of the Fulani pastoral community in educational development in reports.

\subsubsection{Ignorance of Parents on the Importance of Education}

Studies have shown that parents are the bases into community educational development; thus in the pastoral community, the decision to take a child or a family to participant in education is vested on the male parents (Saad, 2002). However, it is evident in this study that, ignorance of parents' on the value of basic education happens to be one of the principal factors to the low level of enrolment, low level of participation and low level of literacy even among the parents of the nomads. As argued by the executive secretary National nomadic education commission that, when you educate the parents definitely they will support the participation of the community in education (Ibrahim, 2014).

Consequently, the study evidently uncovered from the participants that, the level of pastoral Fulani parents' ignorance on the benefit derived from the formal education perceived from their social world, was fundamental to the existing poor participation of the Fulani into the education system in the district. As claimed Fulani parents that not having the opportunity of been enlighten and oriented on it value; thus, augured that, lead parents' to remain ignorant as such influence the negative perception and non-participation of the group in the education system as said some of the participants;

Toh he reacted "Since we that you are discussing with (Fulani parent), do not attain and do not know the impotence of formal education, we do not know its value and its benefit that is just the reason.

"You see... the elders are not educated because of lack of awareness of the importance of the boko".... Adage... but by the time you tested the sweetness of the fruit, I believe you could want your child to follow suite...

These, however, show a strong connection between lacking role with the pulaaku orientation in the community and the level of ignorance of the pastoral parent on education, and low 
participation in education.

This result is in agreement with Raymond, (2012) findings which described the worries about the parents who are yet to perceive the value of educating their children, as it was understood that some that wanted their children to acquire formal education. Corroborating Raymond above, Abdi (2010) findings also concurred that the nomadic kids are psychologically tired out by their parents on acquiring education as they know littlie or not of the significance education have to the child ability and the community benefit, rather than the livestock.

This finding, however, highlighted possibilities of achieving educational development in nomadic pastoral community, whereas, parents were identified as the basis for the success and failure. Hence, should be given priority on the educational issues in the community as the custodian of their moral value.

\section{Conclusion and Recommendations}

The study concluded that pastoral Fulani has a positive perception on education generally for personal and community development. But however, it was found that the low participation of the Fulani in educational community development is influenced by socio-cultural factors such as ignorance of Fulani parent, lake of role model, and the perception of the system as threats to pulaaku moral value and Fulani social capital. Thus, policymakers need to know and consider these factors in designing any educational programme for such marginalised and disadvantaged group.

Therefore, from the finding discussed, the study put forward some suggestions; the need for policymakers, government agencies and stakeholder to go in-depth through sponsoring ethnographic research project to conceptualized the understanding of the pulaaku cultural moral value of the Fulani pastoral group and possibly integrate its ideas into the nomadic education system particularly the values of pulaaku. More also, integrate professional community development worker to encourage and establish community-based volunteer groups, purposively in a constant advocacy awareness, educating and sensitisation of the Fulani parents', and the community on the value of basic formal education and it significance in preserving the pulaaku moral values. This would bridge the gap in missing role model in the pastoral Fulani community. Policy makers and the government should understand that, if the pastoral Fulani parents are educated and enlighten at the beginning, this will go a long way into building a strong confidence and trust into the pastoral Fulani group and the system. This would motivate the Fulani to take up educating the community as an obligation and responsibility to themselves.

\section{Acknowledgement}

The authors would like to extend a special appreciations to the Fulani nomadic community in Ikara district for their willingness to participant in the research work. And Ikara Local Government Education Authority for their support. 


\section{References}

Abdi, A. I. (2010). Education for all (EFA): reaching Nomadic communities in Wajir, Kenya-challenges and opportunities (Doctoral dissertation, University of Birmingham United Kingdom).

Aderinoye, R. A., Ojokheta, K. O., \& Olojede, A. (2007). Integrating mobile learning into nomadic education programme in Nigeria: Issues and perspectives. The International Review of Research in Open and Distributed Learning, 8(2).

AET. (2008). A study of the educational needs of young people in nomadic and pastoralist communities in Somalia, Somali Land and Puntland; by Africa Education Trust http://africaeducationaltrust.org/wp-content/uploads/2014/07/2008-Education-Needs-in-Soma li-Pastoralist-Communities.pdf. (15 ${ }^{\text {th }}$ January, 2015)

Aikman, S., \& Unterhalter, E. (2005). Beyond access: Transforming policy and practice for gender equality in education: Oxfam.

Amadi D. C. (2015), Nomadic Education in Nigeria: Using English to Fuster Communal peace and Enhance the Education of Herdsmen. Global Journal of Arts Humanities and Social Sciences, 3(5), 16-21

Appiah, E. N., \& McMahon, W. W. (2002). The social outcomes of education and feedbacks on growth in Africa. Journal of Development Studies, 38(4), 27-68.

Bah-Lalya, I., Tahir, G., Onocha, C., \& Sukon, K. (2012). Reaching out to the educationally disadvantaged learner in Africa, with particular reference to the Nigerian Case. $A D E A$ working document.

Berinyuy, C. M., \& Spreen, C. A. (2015). 7 Reflections on Identity, Difference, and Rights in an Islamic High School in Cameroon. Educating Adolescent Girls Around the Globe: Challenges and Opportunities, 141.

Bishop, E. (2008). The policy and practice of educational service provision for pastoralists in Tanzania. London, University College of London.

Carr-Hill, R., Ashete, A., Sedel, C., \& de Souza, A. (2005). The Education of Nomadic Peoples in East Africa: Synthesis Report: Djibouti, Eritrea, Ethiopia, Kenya, Tanzania and Uganda: UNESCO-IIEP and African Development Bank.

Carr, W. (1997). Philosophy and method in educational research. Cambridge Journal of Education, 27(2), 203-209.

National Population Commission. (2010). Federal Republic of Nigeria, 2006 population and housing census priority table volume III; population distribution by sex, state, LGA and senatorial district. National Population Commission, Abuja, Nigeria.

Dyer, C. (2010). Education and social (in) justice for mobile groups: re - framing rights and educational inclusion for Indian pastoralist children. Educational Review, 62(3), 301-313. 
Dyer, C., Anteliz, E. A., Coombes, P., \& Danaher, P. (2008). The Education of Nomadic Peoples: Current Issues, Future Prospects [Book Review]. International Journal of Pedagogies and Learning, 4(1), 92.

EFA (2015)“Education for All 2015 National Review Report: Nigeria”, http://unesdoc.unesco.org/images/0023/002310/231081e.pdf

EPDC. (2013). Nigeria Out of school children population ages 7-14, from www.epdc.org.

Green, G. P., \& Haines, A. (2011). Asset building \& community development: Sage.

Hamman, A. U., (2006), "Women Education for Sustainable Development in Nigeria",Education for Sustainable Development in Nigeria. In Ashituabe, G. A. \& Kolo, I. A. Education for Sustainable Development in Nigeria, vol. 1. Minna: Niger State College of Education.

Ibrahim, R. (2014). Housework and education of Fulani girls in Mbang-Fulbe, Northern Cameroon.

Ibrahim, Y. U. A. (2014). Funding, major obstacle to nomadic education - Executive Secretary,DailyTrustfile://C:/Users/USER/Documents/Funding,\%20major\%20obstacle\%20t o\%20nomadic\%20education\%20-\%20Executive\%20Secretary.html (18th January, 2016)

Iro, I. (2006). Nomadic education and education for nomadic Fulani. http://www.gamji.com/fulani7.htm

Kaunga, J. O. (2005). Indigenous peoples' experiences with the formal education system: The case of the Kenyan pastoralists. Indigenous affairs(1), 35-41.

Kratli, S. (2001). Education provision to nomadic pastoralists: A literature review. Institute of Development Studies Working Paper, 126.

Kratli, S., \& Dyer, C. (2006). Education and Development for Nomads: the Issues and the Evidence. The Education of Nomadic Peoples: Current Issues, Future Prospects. New York, Oxford: Berghahn Books, 2006, 8-34.

Larsen, K., \& Hassan, M. (2001). Perceptions of knowledge and coping strategies in nomadic communities-The case of the Hawawir in Northern Sudan. Report-Drylands Coordination Group (Norway).

Merriam, S. (2009). Qualitative Research. A guide to Design and Implementation (Revised and Expanded from Qualitative Research and Case Study Applications in Education): San Francisco: Jossey-Bass.

Michener, H. A., DeLamater, J. D. and Myers, D. J. (2004), Social Psychology (Australia: Thompson Wadsworth), (Fifth Edition), p. 106.

Ombati, V. F \& Ombati, M. (2015). Girl's Education in Kenya's Arid-Semi Arid Zones http://www.culturacritica.cc/2015/03/girls-education-in-kenyas-arid-semi-arid-zones/ (March, 2016) 
Power, C. (2015). Education for All-Milestones and Millstones The Power of Education (pp. 69-88): Springer.

Rao, V. S. P. And Narayana, P. S. (1998), Organisation Theory and Behaviour, (Delhi: Konark Publishing Company), (329-330)

Rao, A., \& Dyer, C. (2006). The acquisition of manners, morals and knowledge: Growing into and out of Bakkarwal society. The education of nomadic peoples: Current issues, future prospects, 53-76.

Raymond, A. (2012). Girls' Education in Pastoral Communities: An Ethnographic Study of Monduli District, Tanzania. Research Report: ERIC.

Riesman, P. (1998). Freedom in Fulani social life: An introspective ethnography: University of Chicago Press.

Rotech, L. C., \& Koros, P. (2015). PASTORALISTS AND GIRL CHILD EDUCATION IN KENYA. International Journal of Innovative Education Research, 3(1),1-13.

Saad, A. M. (2002). Pastoralist children and stakeholders assessment of nomadic education in Nigeria:A tentative report of a consultative survey of nomadic education pupils, communities and the CBOs/ NGOs. Paper presented at the Paper presented at an international conference on nomadic education in Nigeria: Issues and directions by DFID, .16-19 January, 2002, Rockview hotel, Abuja.

Schwartz, S. H. (2006). A theory of cultural value orientations: Explication and applications. Comparative sociology, 5(2), 137-182.

Sharma, A. (2011). South Asian Nomads--A Literature Review. CREATE Pathways to Access. Research Monograph No. 58: ERIC.

Tilde, A. (2005). Enrolment and falling standard of education. Friday Discourse (112). http://www. gamji.com/tilde/tilde.htm(14 ${ }^{\text {th }}$ Octorber, 2015)

Ujorha, T. (2014). Pulaaku: How rustling is crippling this beautiful idea of the Fulbe file://C:/Users/USER/Documents/Pulaaku_\%20How\%20rustling\%20is\%20crippling\%20this \%20beautiful\%20idea\%20of\%20the\%20Fulbe.html( 16th February, 2016) Daily Trust online.

Umar, A., \& Tahir, G. (2000). Researching nomadic education: A Nigerian perspective. International Journal of Educational Research, 33(3), 231-240.

UN. (2015). Resolution adopted by the General Assembly on 25 September 2015 Transforming our world: the 2030 Agenda for Sustainable Development (A/70/L.1) http://www.un.org/ga/search/view_doc.asp?symbol=A/RES/70/1\&Lang=E (24 ${ }^{\text {th }}$ April, 2016) Adopts the following outcome document of the United Nations summit for the adoption of the post-2015 development agenda: . United Nation.

UNESCO. (2007), OPERATIONAL DEFINITION OF BASIC EDUCATION, Thematic Framework http://www.unesco.org/education/framework (24th November, 2016) 


\section{Macrothink}

International Journal of Social Science Research

ISSN 2327-5510 2017, Vol. 5, No. 1

UNESCO-EFA. (2013). EFA global monitoring report: Education transforms lives. Paris: UNESCO.

Unesco, E. (2010). global monitoring report 2010: Reaching the marginalized: UNESCO, Paris.

Usman, L. (2006). Rural nomadic Fulbe boys' primary schooling: assessing repertoires of practice in Nigeria. McGill Journal of Education/Revue des sciences de l'éducation de McGill, $41(2)$.

Victor F, O. O. (2010). Women in the Society: Women participation in education leadership in Kenya Municipal Primary Schools.

Warrington, M., \& Kiragu, S. (2012). "It makes more sense to educate a boy": Girls 'against the odds' in Kajiado, Kenya. International Journal of Educational Development, 32(2), 301-309.

\section{Copyright Disclaimer}

Copyright for this article is retained by the author(s), with first publication rights granted to the journal.

This is an open-access article distributed under the terms and conditions of the Creative Commons Attribution license (http://creativecommons.org/licenses/by/3.0/). 